WellBeing International

WBI Studies Repository

2010

\title{
The State of Human-Animal Studies
}

Kenneth Shapiro

Animals and Society Institute

Margo DeMello

Central New Mexico Community College

Follow this and additional works at: https://www.wellbeingintlstudiesrepository.org/acwp_sata

Part of the Curriculum and Instruction Commons, Humane Education Commons, and the Social and Philosophical Foundations of Education Commons

Recommended Citation

Shapiro, K., \& DeMello, M. (2010). The state of human-animal studies. Society \& Animals, 18(3), 307-318.

This material is brought to you for free and open access by WellBeing International. It has been accepted for inclusion by an authorized administrator of the WBI Studies Repository. For more information, please contact wbisr-info@wellbeingintl.org.

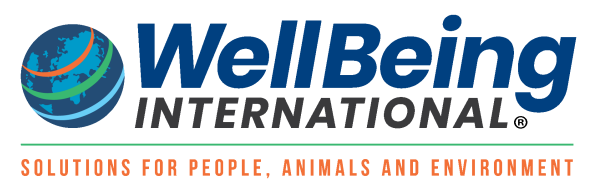




\title{
The State of Human-Animal Studies
}

\author{
Kenneth Shapiro ${ }^{1}$ and Margo DeMello ${ }^{2}$ \\ ${ }^{1}$ Animals and Society Institute \\ ${ }^{2}$ Central New Mexico Community College
}

\section{KEYWORDS}

animal advocacy, human-animal studies, scholarship

\begin{abstract}
The growth of human-animal studies (HAS) over the past twenty years can be seen in the explosion of new books, journals, conferences, organizations, college programs, listserves, and courses, both in the United States and throughout Europe, Australia, New Zealand, and Canada. We look as well at trends in the field, including the increasing popularity of animal-assisted therapy programs, the rise of new fields like trans-species psychology and critical animal studies, and the importance of animal welfare science. We also discuss the problems continuing to face the field, including the conservative culture of universities, the interdisciplinary nature of the field, the current economic crisis, and general anthropocentrism within academia. We end with a discussion of the tension between the scholarly role and the role of animal advocate, and offer some suggestions for HAS to continue to grow.
\end{abstract}

On the occasion of the 10th anniversary of Society \& Animals (Shapiro, 2002), one of us (KS) wrote an editorial outlining the growth of Human-Animal Studies (HAS) in those ten years. Given the pace of the growth of the field in the past eight years, it did not seem prudent to wait for the 20th anniversary to revisit that subject. For the field has not simply grown over the last eight years; it has exploded.

With the publication of Peter Singer's Animal Liberation (1975), followed by Tom Regan's The Case for Animal Rights (1983), there has been a burgeoning interest in animals among academics, animal advocates, and the general public. HAS scholars recognize the lack of scholarly attention given to nonhuman animals and to the relationships between human and nonhuman, especially in the light of the pervasiveness of animal representations, symbols, and stories, as well as the actual presence of animals in human societies and cultures. As feminist scholars began in the 70 s to correct for a male-centered research literature, HAS scholars have begun to insert animals and animal issues into the full range of academic disciplines. As humans' dependence on nonhuman animals increases and as our relationship with them changes in the 21st century, not examining this relationship within the context of academia seems bizarre-especially given the development of animal protection as a social justice movement. 
Following some data demonstrating the growth of HAS, we review changes over the past eight years, first in scholarship, then in institutional development; and we evaluate present trends and their possible future trajectories, highlighting obstacles and pitfalls.

\section{The Explosive Growth of the Field}

There are now 23 college programs in HAS or a related field in the United States, Canada, Great Britain, Germany, Israel, and the Netherlands, as well as an additional eight veterinary school programs in North America, and over 30 HAS organizations in the United States, Canada, Great Britain, Australia, France, Germany, New Zealand, Israel, Sweden, and Switzerland.

Several listserves provide virtual networking for the growing community of HAS scholars and students: $\mathrm{H}$ Animal (627 members), the ASI Human-Animal Studies (846), NILAS (175), and Critical Animal Studies (127).

Including Anthrozoös, which was established in 1987, there are now over a dozen journals covering HAS issues, many of them founded in the last decade. Society \& Animals began in 1992 as a self-published, biannual publication. In 2000 it was acquired by Brill and began to gain more visibility and to broaden its scope from the original social-science focus to include the humanities as well. The newest journal is Humanimalia, an online journal that "aims to signify the many ways that humans and animals are connected: as the experience of animals is shaped by human constructions of them, so is our experience of humanity shaped by non-human animals' constructions of us" (Csicsery-Ronay, 2010).

Scholars researching or teaching HAS have hundreds of books from which to choose. A review of a list of 300 key HAS texts found that well over half of those books were published in the last eight years, with two dozen coming out in 2009 alone. Brill (which publishes ASl's Human-Animal Studies book series), Berg, Johns Hopkins, Purdue, Columbia, Reaktion, Palgrave-McMillan, the University of Minnesota, the University of Illinois, and Oxford all offer either a HAS series or a large number of HAS books.

For HAS courses, we now also have several readers (Between the Species by Arluke and Sanders (2009), Social Creatures by Flynn (2008), and The Animals Reader by Kalof and Fitzgerald (2007), and MD is writing a textbook for Columbia University Press that will be released in 2011. Other key essay collections include The Animal Ethics Reader by Armstrong and Botzler (2003), Animals and Human Society by Manning and Serpell (1994), Representing Animals by Rothfels (2002), and Animal Rights: Current Debates and New Directions by Sunstein and Nussbaum (2002).

While there have been conferences for at least two decades, several HAS conferences were held in 2009, including "Animals: Past, Present and Future," held at Michigan State University in April, "Meet Animal Meat," held at Uppsala University in May, "Human-Animal Interaction: Impacting Multiple Species," held in October in Kansas City, and the largest HAS conference to date, "Minding Animals," held at the University of Newcastle in July; plans are to make "Minding Animals" a triannual, international event.

In 2006, ASI began hosting the Human-Animal Studies Fellowship, a six-week program in which advanced graduate students and postdoctoral scholars work on a HAS research project at a university under the guidance of host scholars and peer scholars working from a distance. The final week of that program has been evolving into a conference of its own; this year's program, to be held at Clark University in Worcester, Massachusetts, promises to be our most exciting yet.

Finally, there are more HAS courses being taught now than ever before. The ASI Web site's course pages list over 300 courses (primarily in North America, but also in Great Britain, New Zealand, Australia, Germany, and Poland) in 29 disciplines at over 200 colleges and universities (Animals \& Society Institute, 
2010). (This does not include the nearly 100 law courses listed separately.) The ASI partners with the Humane Society of the United States in offering the Animals and Society Course Awards, which recognize excellence in HAS courses. Those involved in the selection of the winners have noted that the courses submitted are more sophisticated and diverse than ever before. In 2010, Lantern Press published Teaching the Animal: Human-Animal Studies across the Disciplines (DeMello), an interdisciplinary and multidisciplinary guide for scholars interested in developing or refining courses in HAS.

In the ten-year anniversary issue of Society \& Animals (Shapiro, 2002), KS wrote of the increase in scholarly attention to HAS, and also of many of the obstacles still restricting the growth of the field. At that time, he noted the growth of dissertations in the field, but the lack of institutional bases for HAS research. $\mathrm{He}$ also noted that, at that time, the fields of sociology and psychology were attempting to form HAS sections within their professional organizations. Since then, sociology and psychology have succeeded (the Animals and Society unit in the American Sociological Association; the Animal-Human Interactions section of the Division of Counseling Psychology in the American Psychological Association), as have religion (the Animals and Religion section in the American Academy of Religion), geography (the Animal Geography section in the Association of American Geographers), and philosophy (the Society for the Study of Ethics and Animals).

\section{HAS Scholarship}

\section{Recent History}

As we will discuss below, the multidisciplinarity of HAS presents some problems for its institutional development. It is also an important feature in the proliferation of HAS scholarship, however, as the following admittedly sketchy history demonstrates.

Although it began in a field in the humanities—philosophy (Singer, 1975)—-the initial major growth of HAS was in the social sciences. Anthrozoös and, in its early years, Society \& Animals, primarily published studies in sociology and psychology, featuring a disproportionate number of quantitative studies on human-companion animal relationships. Other disciplines in the social sciences-e.g., anthropology, geography, political science, and legal studies-quickly followed suit, forming core groups of scholars interested in HAS. By the 1990s, humanities disciplines, in addition to philosophy, and more interpretative components of the social sciences increasingly joined the crowd. Much of this latter scholarship occurred under the rubric of the "posts"-post-humanism and postmodernism. Even within philosophy, the second generation of ethicists increasingly excavated the Continental tradition, the seminal ideas from which the "posts" developed, for traces of animal-related ore in Heidegger, Merleau-Ponty, and Derrida. (Singer's utilitarianism had built on analytic philosophy.) An animal-centered literary criticism emerged, applied to both fiction and the visual arts. More recently still, scholars in the natural sciences, notably in cognitive ethology and behavioral neuroscience, have begun to expand the scope of their research from the study of other animals and other animals as models of humans to the direct study of human-animal relationships (Bekoff, 2003).

If only in retrospect, this sequence makes sense. Philosophy raised the question of the valuing or revaluing of nonhuman animals and was a major impetus to the rise of the contemporary animal protection movement. The harder social sciences provided empirical data identifying the amazing array of human-animal relationships, their benefits to humans, and the exploitation typically involved. In response to these developments, in turn, the more interpretive social sciences and humanities delved into the issues on which these relationships rest. Beneath the ethical issues is the "question of the animal." Why do we think about animals in the ways that we do? These foundational issues call into question basic categorical distinctions, such as animal/human, nature/culture, and individual/group. 


\section{Trends and Possible Trajectories}

Where is HAS scholarship going from here? Several existing and emerging trends are noteworthy. How they will affect the actual trajectory of the field is, of course, speculative.

- The dramatic increase in the popularity of animal-assisted therapy and activities sensitizes human service providers to the importance and potential of human-animal relationships, but, at present, continues to reinforce the heavily human-centered focus of attitudes and practices involving animals (Fine, 2001). It is not clear whether its impact will be to produce a constituency of practitioner-scientists who contribute to the broader field of HAS, or to siphon off that potentialand, in particular, undermine efforts in HAS to establish a more bio- or eco-centered paradigm.

- Related to the rise in AAT is the rise in college programs devoted to the human-animal bond. These are found mostly in veterinary school programs but increasingly in regular academic programs as well. Like the AAT courses, however, HAB curricula remain human-centered and focus primarily on the benefits that the bond provides to humans.

- Critical Animal Studies develop and employ an ideological critique of current animal-related institutions, using approaches originating in the Frankfurt School of social criticism and posthumanist thought (White, 2010). CAS is well positioned to tackle foundational conceptual issues underlying the "question of the animal." Their scholarship is unapologetically liberationist and allies with abolitionist and radical elements of the animal protection movement. In an era of center-right politics in the United States and hypersensitivity to radical ideas and direct action, CAS could have a negative impact on public perception both of the movement, and, by association, of HAS. On the other hand, because of its links to the animal rights movement, CAS may be well positioned to help make HAS more relevant to those who work to lessen the suffering and exploitation of animals.

- Animal Welfare Science has established itself as a source of empirical findings on the needs of animals in a variety of settings. Whether the impact of this literature will be limited to the promotion of enhanced well-being of animals and improving the conditions of their use, or will provide empirical grounds for the abolition of those uses, remains to be seen. From its early exclusive focus on the welfare of animals as affected by human-imposed conditions, animal welfare science is increasingly undertaking studies that directly focus on the human-animal relationship (Davis \& Balfour, 1992).

- Trans-Species Psychology applies findings from human psychology to the understanding of other animals, reversing the ethically and scientifically contentious construction of animal models to understand human conditions (Bradshaw, 2009). Extrapolation from human to animal implies similarity across species. Will this bi-directionality reinforce the post-humanist idea of blurred categories, or will it buttress animal-model-based laboratory research, which perennially uses that argument to justify its enterprise? Trans-species psychology does not focus on understanding human-animal relationships, and it names only one discipline. Will it complement or undercut HAS?

As an overview of these trends and possible trajectories, one problematic that is emerging is the tension between animals-as-constructed and the animals-as-such (Shapiro, 2008). Although much remains, considerable work has been done "deconstructing" animals-uncovering the ideological, linguistic, and historical layers that contribute to contemporary attitudes toward, and treatment of, animals. On the one hand, this "discovery" of the inveterately anthropocentric perspective on animals has resulted in a call to study animals for themselves, as they are before we construct them in our own image and for our own 
purposes. This raises epistemological and methodological problems-do we have access to those animals? Increasingly, the sophisticated technology of the hard sciences allows us to "see" animal minds, animals thinking and acting. We discover mirror neurons that, arguably, are the basis of that access (Rizzolatti \& Craighero, 2004). We, human and nonhuman, are hardwired to be sympathetic-to feel with each other, species being no barrier. We are companion species not only through recent history but through our evolutionary history. We discover oxytocin, a hormone that allows us to connect emotionally when we (literally) touch other animals, as well as other humans (Olmert, 2009).

On the other hand, particularly for the radical post-humanist, there is no animal-as-such: it is social construction all the way down (Wolfe, 2010). Deconstructing animals reveals the permanent blur between the species and the shifting nature of the categories "animal" and "human." This enterprise consists of the ongoing study of the amazing complexity and ambiguity of animals and human-animal relationships. The animal-as-such is a chimera and the chimeras are real-any individual is a contingent mix of human, animal, and machine; and the study of human-animal relationships is the study of hybrid relationships.

Social construction, hybridity, and other somewhat arcane concepts (such as "becoming animal") developed in post-humanist literature are intended to replace traditional categorical distinctions, such as animal/human. Some would argue that these concepts provide the necessary foundational work to shift from anthropocentrism, the valorization of everything human, to a fairer deal for other animals. But they can be conceptually hard to digest, and one wonders whether, in an era of sound bites, they can reach and inform public opinion and policy-makers. Another concern is that the specialized language and, really, less analytic and more discursive form of thinking of post-humanism, will widen the unresolved rift between the "two cultures"-interpretative and empirical approaches (Kagan, 2009). If it widens that chasm, post-humanist thought may retard the entry into HAS of the natural sciences, where the study of human-animal relationships is currently least developed. This would be a threat to the truly interdisciplinary nature of the field. Just as significantly, if the natural science side of HAS is not developed, or if it pursues its own independent path, this may prevent HAS from becoming a robust field and a player in the policy arena where the natural sciences typically provide the requisite credibility to the public and attract the most public funding.

\section{HAS Institutional Infrastructure}

\section{Obstacles to Growth}

Although by virtually every measure, the field has expanded its scholarly production, a robust institutional power base for HAS remains to be built. The distribution of HAS scholars nationally at universities remains spotty and diffuse. The increasing but still small number of programs (mostly undergraduate minors and certificates in graduate studies) are underfinanced and marginal. HAS is not establishing institutional-based homes that provide robust and ongoing research programs and a strong platform from which to influence policy related to animal issues.

The obstacles to institutional growth outlined in 2002 (Shapiro) are still present, joined by the substantial economic downturn, which further dims the prospects of growth, particularly growth of an upstart field. Although interdisciplinarity has its advantages for achieving broader understanding of complex phenomena and for developing policy to effect change, it has its downsides. Currently, the primary organizational frame of universities is by discipline. The traditional disciplines run the show and, particularly during hard times, self-protection and maintenance of the status quo are primary concerns.

Reflecting the general culture, university disciplines, including the veterinary sciences and ethology, are strenuously human-centered. Even an ecological perspective and the recognition of a global climate crisis 
are deformed to fit that Procrustean bed. This anthropocentrism combines with the suspicion in some quarters, particularly the biological and psychological sciences, that HAS is a front for animal activism. In a political climate where any form of activism is likely painted with the brush of terrorism, this association adds to the difficulty of HAS truly coming into its own on college campuses. Reinforced by the recent passage of the Animal Enterprise Terrorist Act, many people, both within and outside the university environment, view HAS either as a threat to human interests or as a misuse of human capital in the study of phenomena of secondary, if not trivial, importance. It is not surprising that these nearly polar perceptions duplicate the history of (mis)perceptions of the animal protection movement-from old ladies in tennis shoes to pipe bomb-toting terrorists.

\section{Possible Ways Forward}

As discussed, HAS scholars are increasingly forming networks through conferences, listserves, fellowships, extra-university, cross-discipline study groups, and discipline- or profession-based interest groups. In addition to their primary function of directly enhancing the richness of scholarly production, these networks can work to develop institutional infrastructure. From courses devoted to HAS, to minors, concentrations, majors, certificates, programs, and research institutes, there is a spectrum with increasing potential to increase the field's reach and influence, to attract scholars and funding, and to create a positive cycle of growth. The jewel in the crown of these developments would be a center for HAS. One model is the university-based center for advanced studies. A second is the freestanding think tank, that paradigmatic contemporary institution that weds scholarship to policy development through the production of empirically- and theoretically-based policy papers.

The following are more specific suggestions as to what a center and existing lesser entities might do to increase the institutional base and influence of HAS:

1. Select for study areas of investigation that are topical. Issues involving human-animal relationships continually arise, often with sensational press coverage. In addition to rounding up existing relevant research bearing on problems (animals in natural disasters, or the appropriateness of using dolphins for "therapy," or the plight of the polar bear), scholars can devise investigations that better answer both immediate and underlying conditions.

2. Select for study areas of investigation that connect directly with existing human values. In other words, take advantage of the bias toward human-centered interests. The study of the relationship between human violence and animal abuse, for example, is a bridge to concern about domestic and street violence.

3. Develop working relationships with professionals working in shelters, zoos, sanctuaries, veterinary, and animal-assisted practices. These animal workers are privy to the varied forms of human-animal relationships that are the grist of HAS studies. As they are both guides to and beneficiaries of policy innovation, they are important allies.

4. Develop working relationships with the animal protection movement. The Animal Enterprise Terrorist Act notwithstanding, the center of the contemporary movement has shifted in terms of policy goals and, more important, its modus operandi, making association with it more an opportunity for, than a block to, the growth of HAS. The former is symbolized by the acceptance of the frame of the 3 Rs (refinement, reduction, and replacement; Russell \& Burch, 1959) for animal research, which includes both abolition of exploitative practices and reduction of suffering; the latter by the rise to prominence of more corporate- and establishmentarian-styled organizations, such as the Humane Society of the United States.

5. Develop working relationships with scholars whose study is related to other social justice movements. Women's studies and environmental studies, in particular, overlap with HAS in content areas, critique of current institutions, and an interest in cultural change. 
At present, scholars cannot just devote themselves to scholarship. Regrettably, as for many other callings in contemporary society, for the research enterprise to thrive as a profession requires organizing, branding, marketing, and lobbying for the research dollar. With respect to the institutional development of HAS, scholarship is not enough. We must descend from the ivy tower and brave the murky moats of economics and politics. Networking via list serves and conferences is helpful, but, in addition to the exchange of ideas and social cohesion, these forays must foster exploration of potential forms of organization. We must organize and work to develop institutional infrastructure. This gets us to a final consideration, clarifying the role of the HAS scholar.

\section{The Scholar-Advocate}

A recent article in an environmental studies journal states:

Academic advocacy involves advancing convincingly reasoned arguments that are supported by research results and academic expertise. . . . Advocacy is an important and useful service of the university and failure to advocate undermines the social relevance of academia . . . Advocacy is a core academic activity. (Foote, 2009, p. 579)

Beyond efforts to organize and promote their own profession, scholars have a role to play in establishing their and the academy's "social relevance." This is prudent in a society where the viability of universities is dependent on their economic viability.

Combining advocacy with scholarship is less threatening today, as the thrust of contemporary philosophy of science challenges the received view that it is possible for a scholar not to have a position on the material under investigation. Environmental studies scholars and scholars in developmental psychology necessarily have positions on the importance of the well-being of the environment and on child welfare, and these positions inform their research by shaping the questions they ask, the priorities they establish, and even the investigatory methods they employ. This is not to impugn the validity of findings, as each discipline has its own tried-and-true rules of verification. It is to say that, like every other human enterprise, scholarship is subject to value-laden or "value-informed" (Lynn, 2007) influences that operate both on institutional and individual levels (Latour \& Woolgar, 1979). Although objectivity, the idea of the independent observer, has provided and will continue to provide a powerful and productive regulative ideal, particularly for the natural sciences, there is no view from nowhere (Nagel, 1986).

Reluctance by scholars and the public to accept the social and personal contingencies of scholarly enterprises, their inherent embeddedness in mundane and personal contexts (Latour \& Woolgar, 1979), has constrained development and use of the scholarly community as a resource in policy-making. Until recently, this hesitation has been particularly strong in HAS due to the various obstacles we have described, as well as the status of any novice field. Precedent in other fields and the coming of age of HAS point, however, to the timeliness of HAS scholars being up front with the perspective they generally share and that informs their investigations-that of valuing nonhuman animals.

Explicitly adopting the role of scholar-advocate means recognizing that scholars necessarily wear two hats, roughly representing the virtues of knowledge and of goodness. Minimally, this means that scholars declare their values and acknowledge their presence and influence in their work. An investigator of the physiology or history or ethics of meat-eating indicates his or her own position on this issue in humananimal relationships-in effect, stating what s/he had for dinner and why. It means recognizing that the public inevitably assumes that researchers take a position, no matter how "neutral" their presentation. Or, it might mean devising and presenting empirically- and theoretically-based policy recommendations. Or, now continuing to shift the weight to the advocacy side, it might mean working to organize their primary 
field or HAS as a political interest group. Of course, we cannot all be, nor do we all wish to be, Einstein or Chomsky, or, closer to home, Goodall or Bekoff. Many scholars strive to keep their advocacy hat in the closet or just wear it for special occasions. This is fine, since the two hats are really one.

\section{References}

Animals \& Society Institute. Retrieved April 13, 2010, from www.animalsandsociety.org

Arluke, A., \& Sanders, S. (Eds.). (2009). Between the species: A reader in human-animal relationships. Boston, MA: Pearson Education.

Armstrong, S., \& Botzler, R. (Eds.). (2003). The animal ethics reader. London: Routledge.

Bekoff, M. (2003). Minding animals: Awareness, emotions, and heart. New York: Oxford University Press.

Bradshaw, G. (2009). Elephants on the edge. New Haven: Yale University Press.

Csicsery-Ronay, I. (2010). Humanalia. Retrieved April 13, 2010, from http://www.depauw.edu/humanimalia/humanimalifesto.html

Davis, H., \& Balfour, D. (Eds.). (1992). The inevitable bond: Examining scientist-animal interactions. Cambridge, UK: Cambridge University Press.

DeMello, M. (Ed.). (2010). Teaching the animal: Human-animal studies across the disciplines. New York: Lantern Press.

Fine, A. (Ed.). (2001). Handbook on animal-assisted therapy. Amsterdam: Elsevier.

Flynn, C. (Ed.) (2008). Social creatures: A human and animal studies reader. Brooklyn, NY: Lantern Books.

Foote, L., Krogman, N., \& Spence, J. (2009). Should academics advocate on environmental issues? Society and Natural Resources, 22, 579-589.

Kagan, J. (2009). The three cultures: Natural sciences, social sciences, and the humanities in the $21^{\text {st }}$ Century. Cambridge, UK: Cambridge University Press.

Kalof, L., \& Fitzgerald, A. (Eds.). (2007). The animals reader: The essential classic and contemporary writings. Oxford, UK: Berg.

Latour, B., \& Woolgar, S. (1979). Laboratory life: The construction of scientific facts. Princeton: Princeton University Press.

Lynn, W. (2007). Human-animal studies. In M. Bekoff (Ed.), Encyclopedia of human-animal relationships (Vol. 2, pp. 672-674). Westport CT: Greenwood.

Manning, A., \& Serpell, J. (Eds.). (1994). Animals and human society: Changing perspectives. London: Routledge.

Nagel, T. (1986). The view from nowhere. Oxford, UK: Oxford University Press.

Olmert, M. (2009). Made for each other: The biology of the human-animal bond. Philadelphia: Da Capo Press. 
Regan, T. (1983). The case for animal rights. Berkeley: University of California Press.

Rizzolatti, G., \& Craighero, L. (2004). The mirror-neuron system. Annual Review of Neuroscience, 27, 169-192.

Rothfels, N. (Ed.) (2002). Representing animals. Bloomington, IN: Indiana University Press.

Russell, W., \& Burch, R. (1959). The principles of humane experimental technique. London: Methuen.

Shapiro, K. (2002). Editor's introduction: The state of Human-Animal Studies: Solid, at the margin! Society \& Animals, 10, 331-337.

(2008). Human-Animal Studies: Growing the field, applying the field. Ann Arbor, Ml: Animals and Society Institute.Singer, P. (1975). Animal liberation. New York: Avon Books.

Sunstein, C., \& Nussbaum, M. (Eds.). (2004). Animal rights: Current debates and new directions. Oxford, UK: Oxford University Press.

White, R. (Ed.). (2010). Journal for Critical Animal Studies. Retrieved April 13, 2010, from http://www.criticalanimalstudies.org/?page_id=103

Wolfe, C. (2010). What is posthumanism? Minneapolis: University of Minnesota Press. 